\title{
Molecular characterization of Swiss Ceratopogonidae (Diptera) and evaluation of real-time PCR assays for the identification of Culicoides biting midges
}

\author{
Wenk, C E ; Kaufmann, C ; Schaffner, Francis ; Mathis, Alexander
}

\begin{abstract}
Biting midges of the genus Culicoides (Diptera, Ceratopogonidae) are vectors of several viruses of veterinary relevance, and they can cause insect bite hypersensitivity. As the morphological identification of these tiny insects is a difficult task in many cases, alternative approaches are expedient. With the aim to develop real-time PCRs, we determined partial mitochondrial cytochrome oxidase I gene (mt COI) sequences from 380 Culicoides midges representing three regions of Switzerland, namely the Alps, Midland north of the Alps (Atlantic climate), and South of the Alps (Mediterranean climate). The same region was also sequenced from non-biting midges of the genera Atrichopogon, Brachypogon, Dasyhelea, Forcipomyia and Serromyia. A total of 21 Culicoides species were identified by morphology. Sequence variability (haplotypes) was observed in all species. For each of C. grisescens and C. obsoletus, a novel cryptic species was identified. Whereas all individuals of C. grisescens and of the cryptic C. obsoletus species (O2) originated only from Alpine sites, the known C. obsoletus (O1) species was found in all three regions. Further, a sister taxon to C. pulicaris was identified based on the mt COI sequences and named Culicoides sp. Alignments of available mtCOI sequences from Ceratopogonidae (GenBank, this study) were used to design real-time PCR primers and probes to distinguish C. chiopterus, C. deltus, C. dewulfi, C. grisescens (including the cryptic species), C. imicola, C. lupicaris, C. obsoletus O1, C. obsoletus O2, C. pulicaris, C. scoticus and Culicoides sp. Specificities of primers and probes was tested with cloned targets representing 1 to 4 haplotypes of 18 Culicoides spp. and 1 haplotype each from 4 other Ceratopogonidae. No cross-reactivity was observed when plasmid template representing $5 \times 10(6)$ gene copies was tested, but it was evident ( $\mathrm{Ct}$ values 30 ) in few instances when plasmid template representing $5 \times$ 10(9) gene copies was utilized, the latter corresponding to the total gene copy number (as determined in this study) in 20 insects. The sensitivities of two assays (C. imicola, C. grisescens) were tested by spiking single insects into pools of 99 or 999, randomly selected non-target Ceratopogonidae (with approx. 90\% Culicoides specimens). In the pools of 100 , Ct values were in the range of those obtained with single insects when employing 1\% of the isolated DNA, whereas the sensitivity with the pools of 1000 was low, presumably due to the low DNA concentrations obtained with a protocol that seems inadequate for these larger pools. Thus, the assays as described are applicable for the specific identification of biting midges in small pools. Primers and probes of this study were devised to be suitable for multiplexed assays but these evaluations await to be performed.
\end{abstract}

DOI: https://doi.org/10.1016/j.vetpar.2011.08.034

Posted at the Zurich Open Repository and Archive, University of Zurich

ZORA URL: https://doi.org/10.5167/uzh-61697

Journal Article

Accepted Version 
Originally published at:

Wenk, C E; Kaufmann, C; Schaffner, Francis; Mathis, Alexander (2012). Molecular characterization of Swiss Ceratopogonidae (Diptera) and evaluation of real-time PCR assays for the identification of Culicoides biting midges. Veterinary Parasitology, 184(2-4):258-266.

DOI: https://doi.org/10.1016/j.vetpar.2011.08.034 
1 Molecular characterisation of Swiss Ceratopogonidae (Diptera) and evaluation of real-

2 time PCR assays for the identification of Culicoides biting midges

3

4

5 Claudia E. Wenk, Christian Kaufmann, Francis Schaffner, Alexander Mathis*

6

7

8 Institute of Parasitology, University of Zurich, Winterthurerstr. 266a, 8057 Zurich, 9 Switzerland.

10

11

12 * Corresponding author. Tel.: +41 4463585 01; fax: +41 4463589 07; E-mail address:

13 alexander.mathis@uzh.ch (Alexander Mathis).

14 


\section{ABSTRACT}

Biting midges of the genus Culicoides (Diptera, Ceratopogonidae) are vectors of several viruses of veterinary relevance, and they can cause insect bite hypersensitivity. As the morphological identification of these tiny insects is a difficult task in many cases, alternative approaches are expedient. With the aim to develop real-time PCRs, we determined partial mitochondrial cytochrome oxidase I gene ( $\mathrm{mt} \mathrm{COI}$ ) sequences from 380 Culicoides midges representing three regions of Switzerland, namely the Alps, Midland north of the Alps (Atlantic climate), and South of the Alps (Mediterranean climate). The same region was also sequenced from non-biting midges of the genera Atrichopogon, Brachypogon, Dasyhelea, Forcipomyia and Serromyia. A total of 21 Culicoides species were identified by morphology. Sequence variability (haplotypes) was observed in all species. For each of $C$. grisescens and C. obsoletus, a novel cryptic species was identified. Whereas all individuals of $C$. grisescens and of the cryptic $C$. obsoletus species (O2) originated only from Alpine sites, the known $C$. obsoletus (O1) species was found in all three regions. Further, a sister taxon to $C$. pulicaris was identified based on the $\mathrm{mt} \mathrm{CO}$ sequences and named Culicoides sp. Alignments of available mtCOI sequences from Ceratopogonidae (GenBank, this study) were used to design real-time PCR primers and probes to distinguish $C$. chiopterus, $C$. deltus, $C$. dewulfi, C. grisescens (including the cryptic species), C. imicola, C. lupicaris, C. obsoletus O1, C. obsoletus O2, C. pulicaris, C. scoticus and Culicoides sp. Specificities of primers and probes was tested with cloned targets representing 1 to 4 haplotypes of 18 Culicoides spp. and 1 haplotype each from 4 other Ceratopogonidae. No cross-reactivity was observed when plasmid template representing $5 \times 10^{6}$ gene copies was tested, but it was evident (Ct values $\leq 30$ ) in few instances when plasmid template representing $5 \times 10^{9}$ gene copies was utilized, the latter corresponding to the total gene copy number (as determined in this study) in 20 insects. The sensitivities of two assays (C. imicola, C. grisescens) were tested by spiking single insects into pools of 99 or 999, randomly selected non-target Ceratopogonidae (with approx. $90 \%$ Culicoides specimens). In the pools of 100 , Ct values were in the range of 
42 those obtained with single insects when employing $1 \%$ of the isolated DNA, whereas the 43 sensitivity with the pools of 1000 was low, presumably due to the low DNA concentrations 44 obtained with a protocol that seems inadequate for these larger pools. Thus, the assays as 45 described are applicable for the specific identification of biting midges in small pools. Primers and probes of this study were devised to be suitable for multiplexed assays but these evaluations await to be performed.

49 Keywords:

50 Culicoides, vector identification, barcode, real-time PCR, specificity, cryptic species. 


\section{Introduction}

In northern Europe, biting midges (Diptera, Ceratopogonidae: Culicoides spp.) came to the fore as the putative vectors responsible for the unexpected and explosive spread of the bluetongue virus (BTV) that had been introduced there for the first time in 2006 (Carpenter et al., 2009). A number of Palearctic species of Culicoides have been incriminated as BTV vectors based on virus isolations or detections by real-time PCR from field-caught midges, by host preferences and vector competence studies (summarized in (Pages et al., 2009). Biting midges are the biological vectors of several other viruses which are of relevance for Europe at present: The African horse sickness virus has repeatedly been observed and eradicated in Southern Europe, and new incursions are considered feasible (Mellor and Hamblin, 2004; Zimmerli et al., 2010). Similarly, the epizootic hemorrhagic disease virus which has a wide distribution in the world but has never been observed in Europe has recently expanded to countries neighboring Europe (Anonymous, 2009; Paweska et al., 2005; Yadin et al., 2008). Another virus, most probably transmitted by biting midges, is the Toggenburg orbivirus which has recently been discovered in Switzerland causing mild bluetongue-like symptoms in sheep and clinically unremarkable infections in goats (Chaignat et al., 2009; Hofmann et al., 2008). In addition to this newly recognized role as vectors in Europe, biting midges are a well-known nuisance pest in many parts of the continent and they can cause insect bite hypersensitivity (named colloquially as 'sweet itch') particularly in Equids. Candidate allergens have been characterized from the saliva of model species which can be reared in the laboratory (C. sonorensis, C. nubeculosus) (Hellberg et al., 2009; Langner et al., 2009; Schaffartzik et al., 2010; Wilson et al., 2008) but the species that cause the clinical symptoms under field conditions are not known (Sloet van Oldruitenborgh-Oosterbaan et al., 2009; van der Rijt et al., 2008).

Little data in terms of the Culicoides fauna composition is available for many regions of Europe. In Switzerland, there are 35 established (indigenous) valid species based on published data (Merz et al., 2006). However, several new species have recently been 
reported for the first time from Switzerland, and a number of specimens could not unequivocally be identified by morphology (Cagienard et al., 2006; Casati et al., 2009; Kaufmann et al., 2009). In comparison, 51 species have been listed for north-eastern France, a region which has thoroughly been studied (Delécolle, 1985); Delécolle, personal communication). In order to study the significance of the various Culicoides species with regard to their role as vectors or elicitors of allergy, a comprehensive knowledge of midge fauna as well as tools for their rapid and easy identification are required. Identification at present is primarily carried out using morphological features. The observation of wing patterns allows the classification of the insects into vector-relevant groups such as Obsoletus and Pulicaris and other Culicoides spp. (Goffredo and Meiswinkel, 2004). Further, certain species can be identified based on wing pattern while others require microscopic analysis of slide-mounted parts of the bodies (Campbell and Pelham-Clinton, 1960; Delécolle, 1985). Morphological identification can therefore be a time-consuming procedure and is known to be a very difficult task in many cases even for expert taxonomists (Meiswinkel et al., 2008) due to faint characteristics or intraspecific variability (see Pages et al., 2009). Furthermore, the existence of cryptic species, i.e. morphologically similar midges that are genetically distinguishable, has recently been described (Pages et al., 2009).

Several PCR-based tests have been developed for the identification of Culicoides spp. targeting the ribosomal RNA genes internal transcribed spacer 1 or 2 (ITS-1, ITS-2) or the mitochondrial cytochrome oxidase I gene ( $\mathrm{mt} \mathrm{COI}$, barcode region; (Waugh, 2007). The initial focus of these approaches was to detect $C$. imicola in pools of insects using a conventional PCR targeting ITS-1 (Cêtre-Sossah et al., 2004) which was further developed to real-time quantitative PCRs using SYBR green detection (Cêtre-Sossah et al., 2008; Monaco et al., 2010). Conventional and multiplexed ITS-1or ITS-2 PCRs were further developed for identifying individual insects from the Obsoletus group (Gomulski et al., 2005; Mathieu et al., 2011; Mathieu et al., 2007; Stephan et al., 2009). Relatively few data are available from these genetic loci, and considerable ITS-1 variation within one species has been 
demonstrated (Ritchie et al., 2004). In contrast, sequence information available from the $\mathrm{mt}$ COI locus demonstrates low intra-specific divergence (haplotypes) and high inter-specific differences (Augot et al., 2010; Dallas et al., 2003; Linton et al., 2002; Pages et al., 2009). Several conventional and multiplexed PCRs targeting this $\mathrm{mt}$ COI locus have been published focusing on the detection of a number of Culicoides spp. from the Obsoletus and the Pulicaris groups (Balczun et al., 2009; Nolan et al., 2007; Pages et al., 2009; Schwenkenbecher et al., 2009).

Finally, another molecular technique (matrix-assisted laser desorption/ionization time of flight mass spectrometry; MALDI-TOF MS) has very recently proven its potential for rapid, simple and cost-effective characterization and identification of biting midges (Kaufmann et al., 2011).

The aim of this present study was to develop real-time PCRs for the identification of important biting midges of Switzerland.

\section{Materials and methods}

\subsection{Insects}

Insects were trapped in Switzerland according to the criteria described (Goffredo and Meiswinkel, 2004) with Onderstepoort UV-light suction traps in the framework of a national entomological monitoring programme (Kaufmann et al., 2009). For the present study, the origin of the insects was classified as Alps (altitude $1000-2200 \mathrm{~m} ; 7$ trapping sites), Midland (north of the Alps, altitude $400-700$ m, Atlantic climate; 13 trapping sites) and South (south of the Alps, altitude < $400 \mathrm{~m}$; climate influenced by the Mediterranean Sea; 1 trapping site). Specimens were randomly selected from different catches, and the number of individuals investigated per trapping area roughly corresponds to the trapping effort. Culicoides imicola specimens originated from Corsica (France). Prior to morphological identification and DNA extraction, the midges were kept in $70 \% \mathrm{EtOH}$ at $4{ }^{\circ} \mathrm{C}$. 


\subsection{Morphological identification}

Using a stereo microscope, the Culicoides spp. were separated from the other insects and sorted into Obsoletus group, Pulicaris group and other Culicoides spp. based on wing morphology (Goffredo and Meiswinkel, 2004). Species identification was achieved by microscopic analyses of wing patterns and by the observation of body parts (head, legs, wings and spermatheca of females or complete genitalia of males) of most specimens mounted on slides according to (Delécolle, 1985). The remains of the abdomen and the thorax were stored in $2 \mathrm{ml}$ round-bottom Eppendorf tubes (Schönenbuch, Switzerland) at -20 ${ }^{\circ} \mathrm{C}$ for DNA isolation. Non-biting midges were identified to genus level according to (Wirth et al., 1974)).

\subsection{DNA isolation}

Body parts (see above) or pools of midges were ground in $180 \mu$ l Tris-EDTA buffer $(\mathrm{pH} 8.4$ ) using a mixer mill (Retsch®, MM 300) with one (for single insects) or two (for pools of insects) steel bead(s) (3 mm diameter) at $30 \mathrm{~Hz}$ for $1 \mathrm{~min}$ twice (three times for pooled midges) with an in-between chill down step on ice. The homogenate was then incubated in a heating block for $5 \mathrm{~min}$ at $95^{\circ} \mathrm{C}$, and total DNA was isolated using the Qiamp DNA mini kit (Qiagen, Hombrechtikon, Switzerland) according to the manufacturer's instructions. DNA was eluted in $55 \mu \mathrm{l}$ and was stored at $-20^{\circ} \mathrm{C}$ until further use.

\subsection{Conventional PCRs, cloning, sequencing and data analyses}

Part (585 bp) of the mitochondrial cytochrome oxidase subunit I gene (mt COI) was amplified with the primers C1-J-1718_mod (5'-GGWGGRTTTGGWAAYTGAYTAG-3'), modified from a primer described earlier and incorporating degenerate positions (Dallas et al., 2003), and with the new primer CW1_R (5'-AGHWCCAAAAGTTTCYTTTTTCC-3') designed to be insect-specific. The reaction volume of $50 \mu \mathrm{l}$ consisted of $25 \mu \mathrm{l}$ of the master mix (6 mM $\mathrm{MgCl}_{2}$ ) from the multiplex PCR kit (Qiagen), each primer at a concentration of $1 \mu \mathrm{M}$ and $10 \mu \mathrm{l}$ 
template DNA. Amplifications were done in an automatic thermal cycler (DNA engine, MJ Research, Bio-Rad Laboratories, Basel, Switzerland) with a profile including a HotStarTaq DNA polymerase activation step $\left(95^{\circ} \mathrm{C}\right.$ for $15 \mathrm{~min}$ ) and 40 cycles at $95^{\circ} \mathrm{C}$ for $30 \mathrm{~s}$, annealing at $50^{\circ} \mathrm{C}$ for $30 \mathrm{~s}$ and extension at $72{ }^{\circ} \mathrm{C}$ for $60 \mathrm{~s}$. A final elongation step at $72{ }^{\circ} \mathrm{C}$ for $10 \mathrm{~min}$ was included. PCRs with allegedly Culicoides genus-specific primers (PanCul F / PanCul R targeting the rDNA ITS1 region; genF7 and COIR targeting the $\mathrm{mt} \mathrm{COI}$ ) were done as described (Cêtre-Sossah et al., 2004; Schwenkenbecher et al., 2009).

Cloning of amplicons was achieved using the Topo TA cloning-vector pCR 2.1 (Invitrogen, Carlsbad, CA) according to the manufacturer's manual. The plasmids were purified using the Qiaprep spin miniprep kit (Qiagen) following the manufacturer's instructions. DNA concentration was measured using a Nanodrop photometer (NanoDrop products, Wilmington, USA), the plasmids diluted to stock solutions of $10^{9}$ copies/ $\mu$ l and stored at -20 ${ }^{\circ} \mathrm{C}$. Glycerol stocks of transfected bacteria in glycerol (Sigma, Buchs, Switzerland) are kept at $-80^{\circ} \mathrm{C}$.

Sequencing of amplicons, either directly after purification with the minelute PCR purification kit (Qiagen) or after cloning, was done by a private company (Synergene $\mathrm{GmbH}$, Schlieren, Switzerland).

Dendrograms were inferred from sequences aligned with ClustalW and from NeighborJoining (NJ) analyses using the software MEGA, version 4.1 (Tamura et al., 2007), with default settings.

\subsection{Primer and probe design for species-specific real-time PCR assays}

Partial mt COI sequences determined in this study and corresponding ones retrieved from GenBank were aligned using Multalin (Corpet, 1988). If necessary, the sequences were manually adjusted. In a stepwise approach, consensus sequences of the species were identified, and appropriate primers and probes were designed using the software Primer Express 1.5TM. If required, the primers were designed degenerated to account for haplotype 
variability and/or manually designed, and their annealing temperature was calculated using the program PerlPrimer. The primers and probes were tested for the formation of dimers and hairpins using AutoDimerv1 software (default settings). Oligonucleotides that had $\Delta \mathrm{G}$ values higher than $-5 \mathrm{kcal} / \mathrm{mol}$ at $37{ }^{\circ} \mathrm{C}$ were redesigned. Primers and probes were ordered at Microsynth AG (Balgach, Switzerland), except for the minor groove binding (MGB) probes which were synthesized by Applied Biosystems (Rotkreuz, Switzerland). The ordinary Taqman probes were PAGE purified and the MGB probes were HPLC purified.

\subsection{Real-time PCRs, diagnostic parameters}

PCRs were done in duplicates in $25 \mu$ volumes including $12.5 \mu \mathrm{l}$ iQ multiplex powermix (BioRad Laboratories, Basel, Switzerland), $2.5 \mu \mathrm{l}$ of each primer and probe and $5 \mu \mathrm{l}$ template DNA. The reactions were run in an iCycler (Bio-Rad) in 96 well plates using the following cycling conditions: $95{ }^{\circ} \mathrm{C}$ for $3 \mathrm{~min}$ (hotstart), 35 cycles at $95{ }^{\circ} \mathrm{C}$ for $15 \mathrm{~s}$ and $60{ }^{\circ} \mathrm{C}$ for $1 \mathrm{~min}$. All results were expressed in Ct values at a fixed threshold (default settings). The optimal concentrations of primers $(50 \mathrm{nM}, 300 \mathrm{nM}$ or $900 \mathrm{nM})$ and probes $(50 \mathrm{nM}, 100 \mathrm{nM}$ or 200 $\mathrm{nM}$ ) were determined. The specificities of the primers and probes were tested with $5 \times 10^{6}$ and $5 \times 10^{9}$ copies of the cloned target of other Culicoides spp. and other Ceratopogonidae as template DNA (see table 2). The number of $\mathrm{mt} \mathrm{COI} \mathrm{copies} \mathrm{per} \mathrm{individual} \mathrm{insect} \mathrm{was}$ calculated for 4 Culicoides species (C. scoticus, C. dewulfi, C. imicola and C. pulicaris) based on standard curves obtained with three concentrations $\left(5 \times 10^{6}, 5 \times 10^{4}\right.$ and $5 \times 10^{3}$ copies) of the corresponding cloned target sequence. The sensitivity of two assays was evaluated by analyzing five pools each of single target individuals ( $C$. imicola or $C$. grisescens) added to 99 or 999 randomly selected other Culicoides spp. and approx. $10 \%$ non-biting midges before DNA extraction.

\section{Results}

\subsection{Morphological and genetic identification of midges}


A total of 380 Culicoides midges from three regions of Switzerland (Alps, Midland north of the Alps with Atlantic climate, South of the Alps with Mediterranean climate) were identified by microscopic analyses of mounted specimens and by determining partial sequences (465 $541 \mathrm{bp}$ ) of the $\mathrm{mt} \mathrm{COI}$ gene. In addition, 21 insects belonging to 5 genera of non-biting midges and $C$. imicola specimens from Corsica (France) were treated alike (Table 1). The biting midges (Culicoides spp.) could be assigned to 21 established species with a preponderance of members of the Obsoletus group, in particular C. scoticus (Table 1). For each C. grisescens and C. obsoletus, a novel cryptic species was identified, i.e. morphologically indistinguishable midges with distinctly different $\mathrm{mt} \mathrm{CO}$ sequences (Figs. $1 \mathrm{~A}$ and $\mathrm{B}$; designation according to the suggested nomenclature for cryptic species of (Pages et al., 2009), as C. grisescens $\mathrm{G} 1$ and $\mathrm{G} 2$; C. obsoletus $\mathrm{O} 1$ and $\mathrm{O} 2$, respectively, for the established and the new cryptic species). Translational analyses of the sequences from $C$. obsoletus $\mathrm{O} 1$ and $\mathrm{O} 2$ using the invertebrate mitochondrial code revealed functional genes differing by 1-2 amino acids (aa) among the total 176 aa. Sequence analyses of a second locus (rDNA ITS1) showed low intra-species variability of the cloned amplicons from two individuals each of $C$. obsoletus $\mathrm{O} 1$ and $\mathrm{O} 2$ and a $2.8 \%$ inter-species diversity, placing the two species in different clusters in a dendrogram (not shown). In addition, a genetically separate cluster of sequences was identified as a sister taxon to $C$. pulicaris (Fig. 1B). As the careful morphological analyses of these insects yielded different species identifications, including C. lupicaris (most specimens),

C. Iupicaris/pulicaris intermediate phenotype, atypical $C$. pulicaris and $C$. deltus, the midges from this cluster were not considered a cryptic species but were tentatively named Culicoides sp. The 12 haplotypes of the 34 individuals investigated divide into two branches (Fig 1B), but these do not reflect the morphological heterogeneity observed, as e.g. the 4 midges identified as $C$. deltus are found on both branches (nos. 360-363). Around half of the species were collected from only one of the three regions, e.g. C. deltus, 
C. dewulfi and $C$. lupicaris were identified from Midland traps only. Other species $(C$. chiopterus, C. obsoletus 01, C. pulicaris and C. scoticus) were present in all three climate regions. The genetic variability of important species (Obsoletus and Pulicaris groups, C. dewulfi) and of the new Culicoides sp. (Table 1A) was further analyzed. A certain degree of intra-species sequence variability (haplotypes) was observed in all species (Figs. 1A and B), e.g. 10 haplotypes were determined for the 20 specimens of $C$. lupicaris and 11 haplotypes for the 104 C. scoticus insects (for number of insects investigated see table 1). Within the species that occurred in all three investigated areas (C. chiopterus, C. obsoletus $01, C$. pulicaris and C. scoticus), no obvious clustering of haplotypes according to the geographic origin was observed. The sequence data are available in GenBank under accession numbers HQ824371to HQ824525.

251

\subsection{Development of real-time PCRs}

Eleven real-time PCR assays targeting the $\mathrm{mt}$ COI gene were developed for the specific identification of Culicoides (Tables 1A, 2): C. chiopterus, C. deltus, C. dewulfi, C. grisescens (for both $\mathrm{G} 1$ and G2), C. imicola, C. lupicaris, C. obsoletus O1, C. obsoletus O2, C. pulicaris, C. scoticus, Culicoides sp. Primers and probes were designed in silico by considering all sequence information available (GenBank, this study) for Ceratopogonidae. The optimal concentrations for primers and probes were assessed (table 2), and the specificities of the assays were evaluated by PCRs with cloned targets $(n=40)$ of 1 to 4 haplotypes from 18 Culicoides spp. and of 1 haplotype each of 4 other Ceratopogonidae which are regularly found in the UV-light traps (Table 2). Hence, when testing $5 \times 10^{6}$ targets of the appropriate species, Ct values between 18.6 and 20 were observed, and all tests with targets from other species were negative. Using 1000-fold higher concentrations of target molecules $\left(5 \times 10^{9}\right)$ yielded $\mathrm{Ct}$ values of $8.5-10.5$ for the proper targets, and cross-reactivity ( $\mathrm{Ct}$ values $\leq 30$ ) was observed in a few instances (Table 2). 
The number of targets (mitochondrions) in single insects was evaluated for $C$. dewulfi, $C$. imicola, C. pulicaris and C. scoticus, based on standard curves obtained with the respective cloned sequences. Hence, $3.4 \times 10^{7}$ to $2.8 \times 10^{8}$ copies per single biting midge were calculated.

Finally, the sensitivities of the two assays for detection of $C$. imicola and $C$. grisescens were tested with spiked pools. DNA concentrations obtained from these pools ranged from 107 to $130 \mathrm{ng} / \mu \mathrm{l}$ (100 insects/pool), but were as low as 14 to $39 \mathrm{ng} / \mu \mathrm{l}$ for the larger pools (1000 insects). Real-time PCRs with $5 \mu \mathrm{l}$ DNA solutions from the pools of 100 mostly were negative. These tests were repeated with $0.5 \mu$ DNA solutions (i.e. $5 \mu$ l of a 1:10 dilution). Hence, one C. imicola or C. grisescens specimen in total 100 midges was detectable with $\mathrm{Ct}$ values between $20.8-22.6$ (C. imicola) or $21.9-23.9$ (C. grisescens); these values being between $22.9-28.4$ or $26.1-30.9$, respectively, when investigating undiluted DNA from the pools containing 1000 insects.

\section{Discussion}

\subsection{Real-time PCRs}

Culicoides specimens usually are pre-sorted by morphological features into Obsoletus group, Pulicaris group and other Culicoides spp. The very initial aim of the present study was to develop a triplex real-time PCR to accomplish the same task, with the intrinsic added potential value of also gaining quantitative estimates of the composition of insect pools. However, the extensive analyses of huge numbers of $\mathrm{mt} \mathrm{COI}$ sequences from Culicoides spp., either retrieved from GenBank or determined during this study, revealed that this posed an unsolvable challenge for us. Hence, we focused on developing real-time PCR assays for the identification of specific Culicoides biting midges (Tables 1A, 2). For the first time, also corresponding sequences of non-biting midges, which are usual by-catches in light traps, were determined and taken into consideration when designing the Culicoides primers and probes. The necessity of this approach is illustrated by the fact that primers that were 
described as being specific for the genus Culicoides also amplify DNA from the non-biting midges investigated in this study (see Table 1; results not shown). Hence, the primers genF7/COIR (Schwenkenbecher et al., 2009) targeting the mt COI have identical or highly similar sequences to the respective gene sequences of these non-biting midges, and the expected amplicon of 104 bp was obtained when performing that particular PCR assay e.g. with DNA from Forcipomyia sp. Further, supposedly genus-specific primers targeting the $18 \mathrm{~S}$ and 5.8S rRNA genes and flanking the ITS1 (Cêtre-Sossah et al., 2004) readily produced amplicons in the range of $300-550$ bp with DNA from the non-biting midges.

The existence of genetic variants (haplotypes) was found in all investigated species. For some of the target midges, degenerate primers had to be designed to account for this sequence heterogeneity at those gene sequence regions which were identified as suitable markers for a species (by reasonably differing from all other available sequences). Further, as the target gene is rather rich in $\mathrm{A} / \mathrm{T}$, minor groove binding probes were chosen in some instances to allow for a high specificity of shorter oligonucleotides (Yao et al., 2006).

Specificities of the assays were tested with two concentrations of cloned targets of 22 other midge species, with several haplotypes being tested for some species. Hence, no cross reactivities of the assays were observed when investigating $5 \times 10^{6}$ targets, whereas the 1000 fold higher concentrations yielded weak reactions in some instances. These crossreactions, which interestingly mostly occurred only with a single haplotype of a species, were rather unexpected, as primers and probes were designed with several mismatches to nontarget sequences, particularly at the $3^{\prime}$ end and in the middle, respectively. For example the probe of $C$. scoticus has 6 mismatches (length of probe: $27 \mathrm{nt}$ ) and both primers 2 mismatches with the sequence of the cloned haplotype of $C$. chiopterus with which a $\mathrm{Ct}$ value of 26 was obtained in the real-time PCR spiked with $5 \times 10^{9}$ targets (Table 2). However, the number of non-target DNA used in these assays $\left(5 \times 10^{9}\right)$ was very high, corresponding to the total number of target genes of at least 20 such non-target midges (which contain between $3.4 \times 10^{7}$ to $2.8 \times 10^{8}$ copies of the gene). As outlined below, the total 
DNA of this number of insects in a single assay might be too high and cause inhibition of the reaction. Hence, these cross reactivities might be of little concern for practical purposes, and it must be stressed that such evaluations of other published PCR assays were done with DNA aliquots obtained from single biting midges of mostly a limited number only of nontarget Culicoides species.

Real-time PCRs with DNA from pools of 100 midges for the detection of a single spiked target species was successful when employing $1 \%$ of the DNA but were hampered when using $10 \%$, probably due to PCR inhibition. By using $1 \%$ of the DNA, approx. $10^{6}$ targets of the spiked individual are present in the reactions. The $\mathrm{Ct}$ values in these assays were around 21 for the detection of $C$. imicola which very well match the value of around $19-20$ when testing $5 \times 10^{6}$ cloned targets (Table 2 ). Hence, this assay is highly sensitive and specific for the detection of a single midge in pools of at least 100. In contrast, DNA isolation from pools of 1000 midges yielded low concentrations, and the protocol applied needs to be improved. However, investigating larger pools of midges might in a few cases give false-positive results, e.g. when using the $C$. chiopterus assay with DNA obtained from pools containing huge numbers of $C$. scoticus (Table 2). Thus, our approach is applicable for the specific identification of midges in pools of less than 1000 midges.

The primers and probes of this study were devised to be suitable for multiplexed assays, i.e. all were analyzed for the formation of dimers with any other oligonucleotide and redesigned if necessary. The fluorophores of the probes (Table 2) were chosen to allow triplex assays e.g. a 'bluetongue panel' targeting the major vector species $C$. imicola, C. obsoletus $\mathrm{O} 1$ and $C$. scoticus, a 'Pulicaris group panel' covering C. pulicaris, C. lupicaris, and C. grisescens (both G1 and G2), or an 'alpine panel' including C. deltus, C. obsoletus $\mathrm{O} 2$ and Culicoides sp. which nearly exclusively have been collected at higher altitudes. However, these investigations have not yet been accomplished, and other combinations with the single assays described (Table 2) are feasible, possibly after adjusting the fluorophores. 


\subsection{Cryptic species/Culicoides sp.}

The analyses of partial mt COI sequences confirmed earlier findings (Augot et al., 2010; Calvo et al., 2009; Dallas et al., 2003; Linton et al., 2002; Pages et al., 2009; Pages and Sarto, 2005) that this locus displays low intra-specific variation and considerable interspecific variation in Culicoides spp. These analyses also revealed the presence of two new cryptic species, morphologically indistinguishable from $C$. grisescens and $C$. obsoletus, respectively, but differing by $10-11 \%$ at nucleotide level of the $\mathrm{mt}$ COI locus. Such cryptic species have recently been described for the first time in the genus Culicoides in three $(C$. fagineus, C. newsteadi and C. pulicaris) of five investigated species (Pages et al., 2009) by analyzing the same genetic locus as addressed in our study. An alternative explanation of this observed genetic variability could be the existence of mitochondrial DNA sequences that integrated in the nuclear genome (nuclear mtDNA, 'NUMT') and evolved as pseudogenes. Such NUMT elements have been identified in some insects (Sunnucks and Hales, 1996; Zhang and Hewitt, 1996), but recent analyses of insect genomes have revealed that in general they are scarce. The two hitherto recognized exceptions among insects are the honey bee Apis mellifera and the yellow fever mosquito Aedes aegypti which have plenty of NUMTs (summarized in (Black and Bernhardt, 2009). Translational analyses of the mt COI sequences of the cryptic species $C$. grisescens $\mathrm{G} 2$ and $C$. obsoletus $\mathrm{O} 2$ confirmed that these novel sequences encode for proteins (i.e. no frame shifts or stop codons present). In addition, analyses of $C$. obsoletus $\mathrm{O} 2$ at a second locus (rDNA ITS) confirmed its distinctness from and relatedness to $C$. obsoletus 01 . Further, real-time PCRs with primers and probes targeting $C$. obsoletus $\mathrm{O} 1$ were negative on DNA from 2 individuals identified as C. obsoletus $\mathrm{O} 2$, and vice versa (not shown). Finally, mass spectrometric analyses by MALDI-TOF allow to differentiate between $C$. grisescens $\mathrm{G} 1$ and G2 (own unpublished data; C. obsoletus not investigated).

A puzzling finding was the variability of the morphological species designation of specimens which genetically clustered as sister taxon of $C$. pulicaris and which were named Culicoides 
sp. For the morphological identification of midges species belonging to the Pulicaris group, the decisive criterion using currently available identification keys (Delécolle, 1985) is the wing pattern, all other features considered being non-discriminative. Intra-specific morphological variation has been observed in various species (literature compiled in (Pages et al., 2009), and obviously midges of the newly described species (designated Culicoides sp.) display variability in wing patterns causing uncertain identifications. Closer morphometric analyses of these items might allow devising a more precise key with reliable parameters. A similar approach has recently been described for the differentiation of $C$. obsoletus and $C$. scoticus females which were considered undistinguishable (Augot et al., 2010). A cryptic species of $C$. pulicaris, designated C. pulicaris P3, has recently been identified (Pages et al., 2009). These specimens were morphologically not discriminable from $C$. pulicaris and their $\mathrm{mt}$ COI sequences considerably differ (not shown) from those of the Culicoides sp. identified in Switzerland. Hence, based on the genetic data and on the morphological ambivalence, Culicoides sp. indeed seems to be a novel species.

\subsection{Geographical distribution of species/haplotypes}

Several Culicoides species have only been found in one of the three investigated climatic regions of Switzerland (Alps, midland north of the Alps with Atlantic climate, region south of the Alps with Mediterranean climate), but, clearly, the number of investigated specimens is too low to draw conclusions on their definitive geographic distribution. Interestingly, both discovered cryptic species (C. grisescens G2, C. obsoletus O2) were only sampled in the Alpine region; from the new species Culicoides sp. all but one specimen also originated from higher altitudes. It remains to be elucidated whether these species are truly adapted to this climate.

Specimens from 4 species (C. chiopterus, C. obsoletus 01, C. pulicaris and C. scoticus) were collected in all three climatic regions, and no clustering of haplotypes according to the geographic origin was obvious. Thus, the alpine crest seems not to be a barrier for the 
dispersal of these midges. Further, co-clustering of $\mathrm{mt} \mathrm{COI} \mathrm{sequences} \mathrm{with} \mathrm{those} \mathrm{from} \mathrm{Swiss}$ midges is observed for sequences from Spain (C. pulicaris, C. scoticus), Great Britain (C. pulicaris, C. grisescens G1, C. scoticus, C. chiopterus, C. dewulfi) and from Bulgaria (C. obsoletus O1) (Figs. 1A and B), indicating a lack of barriers for these species in Europe. In contrast, Spanish C. obsoletus $\mathrm{O} 1$ and $C$. lupicaris are placed on separate branches, supported by high bootstrap values (Fig. 1). Therefore, the population genetic structure of the investigated midge species might differ across Europe, and this is of ecological and epidemiological significance, particularly with regard to vector competence.

\section{Acknowledgements}

We kindly thank Jeannine Hauri for her excellent technical support in the lab and all the farmers for carefully and reliably running the light traps. Furthermore, we are indebted to $\mathrm{Dr}$. J.-C. Delécolle (Université Louis Pasteur, Strasbourg) for his inestimable assistance in the morphological identification of many of our trapped Ceratopogonidae biting midges and for providing the $C$. imicola specimens. This study was funded by the Swiss Federal Veterinary Office (project No. 1.08.10) and represents the doctoral thesis of Claudia E. Wenk, veterinarian.

\section{References}

\section{References}

Anonymous, 2009. Scientific opinion on epizootic hemorrhagic disease. EFSA Journal 7(12), Document 1418, $67 \mathrm{pp}$.

Augot, D., Sauvage, F., Jouet, D., Simphal, E., Veuille, M., Couloux, A., Kaltenbach, M.L., Depaquit, J., 2010. Discrimination of Culicoides obsoletus and Culicoides scoticus, potential bluetongue vectors, by morphometrical and mitochondrial cytochrome oxidase subunit I analysis. Infect. Genet. Evol. 10, 629-637. 
Balczun, C., Vorsprach, B., Meiser, C.K., Schaub, G.A., 2009. Changes of the abundance of Culicoides obsoletus s.s. and Culicoides scoticus in Southwest Germany identified by a PCR-based differentiation. Parasitol. Res. 105, 345-349.

Black, W.C., Bernhardt, S.A., 2009. Abundant nuclear copies of mitochondrial origin (NUMTs) in the Aedes aegypti genome. Insect Mol. Biol. 18, 705-713.

Cagienard, A., Griot, C., Mellor, P.S., Denison, E., Stärk, K.D.C., 2006. Bluetongue vector species of Culicoides in Switzerland. Med. Vet. Entomol. 20, 239-247.

Calvo, J.H., Calvete, C., Martinez-Royo, A., Estrada, R., Miranda, M.A., Borras, D., Sarto, I.M.V., Pages, N., Delgado, J.A., Collantes, F., Lucientes, J., 2009. Variations in the mitochondrial cytochrome c oxidase subunit I gene indicate northward expanding populations of Culicoides imicola in Spain. Bull. Entomol. Res. 99, 583-591.

Campbell, J.A., Pelham-Clinton, E.C., 1960. A taxonomic review of the British species of Culicoides Latreille (Diptera, Ceratopogonidae). Proc. R. Soc. Edinburgh, Section B $67,181-302$.

Carpenter, S., Wilson, A., Mellor, P.S., 2009. Culicoides and the emergence of bluetongue virus in northern Europe. Trends Microbiol. 17, 172-178.

Casati, S., Racloz, V., Delécolle, J.-C., Mathis, A., Griot, C., Stärk, K.D.C., Vanzetti, T., 2009. An investigation on the Culicoides species composition at seven sites in southern Switzerland. Med. Vet. Entomol 23, 93-98.

Cêtre-Sossah, C., Baldet, T., Delécolle, J.-C., Mathieu, B., Perrin, A., Grillet, C., Albina, E., 2004. Molecular detection of Culicoides spp. and Culicoides imicola, the principal vector of bluetongue (BT) and African horse sickness (AHS) in Africa and Europe. Vet. Res. 35, 325-337.

Cêtre-Sossah, C., Mathieu, B., Setier-Rio, M.L., Grillet, C., Baldet, T., Delécolle, J.-C., Albina, E., 2008. Development and evaluation of a real-time quantitative PCR assay for Culicoides imicola, one of the main vectors of bluetongue (BT) and African horse sickness (AHS) in Africa and Europe. Res. Vet. Sci. 85, 372-382. 
Chaignat, V., Worwa, G., Scherrer, N., Hilbe, M., Ehrensperger, F., Batten, C., Cortyen, M., Hofmann, M., Thuer, B., 2009. Toggenburg orbivirus, a new bluetongue virus: initial detection, first observations in field and experimental infection of goats and sheep. Vet. Microbiol. 138, 11-19.

Corpet, F., 1988. Multiple sequence alignment with hierarchical clustering. Nucleic Acids Res. 16, 10881-10890.

Dallas, J.F., Cruickshank, R.H., Linton, Y.M., Nolan, D.V., Patakakis, M., Braverman, Y., Capela, R., Capela, M., Pena, I., Meiswinkel, R., Ortega, M.D., Baylis, M., Mellor, P.S., Mordue (Luntz), A.J., 2003. Phylogenetic status and matrilineal structure of the biting midge, Culicoides imicola, in Portugal, Rhodes and Israel. Med. Vet. Entomol. $17,379-387$.

Delécolle, J.-C., 1985. Nouvelle contribution à l'étude systématique et iconographique des espèces du genre Culicoides (Diptera: Ceratopogonidae) du Nord-Est de la France. Université Louis Pasteur, Strasbourg, 238 pp., Reissue 1993.

Goffredo, M., Meiswinkel, R., 2004. Entomological surveillance of bluetongue in Italy: methods of capture, catch analysis and identification of Culicoides biting midges. Vet. Ital. 40, 260-265.

Gomulski, L.M., Meiswinkel, R., Delécolle, J.-C., Goffredo, M., Gasperi, G., 2005. Phylogenetic relationships of the subgenus Avaritia Fox, 1955 including Culicoides obsoletus (Diptera, Ceratopogonidae) in Italy based on internal transcribed spacer 2 ribosomal DNA sequences. Syst. Entomol. 30, 619-631.

Hellberg, W., Mellor, P.S., Torsteinsdottir, S., Marti, E., 2009. Insect bite hypersensitivity in the horse: comparison of lgE-binding proteins in salivary gland extracts from Simulium vittatum and Culicoides nubeculosus. Vet. Immunol. Immunopathol. 132, 62-67. 
Hofmann, M.A., Renzullo, S., Mader, M., Chaignat, V., Worwa, G., Thuer, B., 2008. Genetic characterization of toggenburg orbivirus, a new bluetongue virus, from goats, Switzerland. Emerg. Infect. Dis. 14, 1855-1861.

Kaufmann, C., Schaffner, F., Mathis, A., 2009. Monitoring of biting midges (Culicoides spp.), the potential vectors of the bluetongue virus the 12 climatic regions of Switzerland. Schweiz. Arch. Tierheilkd. 5, 205-513.

Kaufmann, C., Ziegler, D., Schaffner, F., Carpenter, S., Pflüger, V., Mathis, A., 2010. Evaluation of matrix-assisted laser desorption/ionization time of flight mass spectrometry for characterization of Culicoides nubeculosus biting midges. Med. Vet. Entomol., 25, 32-38.

Langner, K.F., Jarvis, D.L., Nimtz, M., Heselhaus, J.E., McHolland, L.E., Leibold, W., Drolet, B.S., 2009. Identification, expression and characterisation of a major salivary allergen (Cul s 1) of the biting midge Culicoides sonorensis relevant for summer eczema in horses. Int. J. Parasitol. 39, 243-250.

Linton, Y.M., Mordue (Luntz), A.J., Cruickshank, R.H., Meiswinkel, R., Mellor, P.S., Dallas, J.F., 2002. Phylogenetic analysis of the mitochondrial cytochrome oxidase subunit I gene of five species of the Culicoides imicola species complex. Med. Vet. Entomol. $16,139-146$.

Mathieu, B., Delecolle, J.-C., Garros, C., Balenghien, T., Setier-Rio, M.-L., Candolfi, E., Cêtre-Sossah, C., 2011. Simultaneous quantification of the relative abundance of species complex members: Application to Culicoides obsoletus and Culicoides scoticus (Diptera: Ceratopogonidae), potential vectors of bluetongue virus. Vet. Parasitol., doi:10.1016/j.vetparas.2011.05.052 (corrected proof).

Mathieu, B., Perrin, A., Baldet, T., Delecolle, J.-C., Albina, E., Cêtre-Sossah, C., 2007. Molecular identification of Western European species of Obsoletus complex (Diptera: Ceratopogonidae) by an internal transcribed spacer-1 rDNA multiplex polymerase chain reaction assay. J. Med. Entomol. 44, 1019-1025. 
Meiswinkel, R., Baldet, T., de Deken, R., Takken, W., Delécolle, J.-C., Mellor, P.S., 2008. The 2006 outbreak of bluetongue in northern Europe - the entomological perspective. Prevent. Vet. Med. 87, 55-63.

Mellor, P.S., Hamblin, C., 2004. African horse sickness. Vet. Res. 35, 445-466.

Merz, B., Bächli, G., Haenni, J.-P., 2006. Zweiter Nachtrag zur Ckeckliste der Diptera der Schweiz. Mitt. Schweiz. Entomol. Gesell. 56, 135-165.

Monaco, F., Benedetto, L., Di Marcello, V., Lelli, R., Goffredo, M., 2010. Development and preliminary evaluation of a real-time polymerase chain reaction for the identification of Culicoides obsoletus sensu strictu, C. scoticus and C. montanus in the Obsoletus complex in Italy. Vet. Ital. 46, 209-214.

Nolan, D.V., Carpenter, S., Barber, J., Mello, P.S., Dallas, J.F., Mordue, J.A., Piertney, S.B., 2007. Rapid diagnostic PCR assay for members of the Culicoides obsoletus and Culicoides pulicaris species complexes, implicated vectors of bluetongue virus in Europe. Vet. Microbiol. 124, 82-94.

Pages, N., Munoz-Munoz, F., Talavera, S., Sarto, V., Lorca, C., Nunez, J.I., 2009. Identification of cryptic species of Culicoides (Diptera: Ceratopogonidae) in the subgenus Culicoides and development of species-specific PCR assays based on barcode regions. Vet. Parasitol. 165, 298-310.

Pages, N., Sarto, I.M.V., 2005. Differentiation of Culicoides obsoletus and Culicoides scoticus (Diptera: Ceratopogonidae) based on mitochondrial cytochrome oxidase subunit I. J. Med. Entomol. 42, 1026-1034.

Paweska, J.T., Venter, G.J., Hamblin, C., 2005. A comparison of the susceptibility of Culicoides imicola and C. bolitinos to oral infection with eight serotypes of epizootic haemorrhagic disease virus. Med. Vet. Entomol. 19, 200-207.

Ritchie, A., Blackwell, A., Malloch, G., Fenton, B., 2004. Heterogeneity of ITS1 sequences in the biting midge Culicoides impunctatus (Goetghebuer) suggests a population in Argyll, Scotland, may be genetically distinct. Genome 47, 546-558. 
Schaffartzik, A., Marti, E., Torsteinsdottir, S., Mellor, P.S., Crameri, R., Rhyner, C., 2010. Selective cloning, characterization, and production of the Culicoides nubeculosus salivary gland allergen repertoire. Vet. Immunol. Immunopathol. (in press).

Schwenkenbecher, J.M., Mordue, A.J., Switek, K., Piertney, S.B., 2009. Discrimination of Culicoides midge larvae using multiplex polymerase chain reaction assays based on DNA sequence variation at the mitochondrial cytochrome C oxidase I gene. J. Med. Entomol. 46, 610-614.

Sloet van Oldruitenborgh-Oosterbaan, M.M., van Poppel, M., de Raat, I.J., van den Boom, R., Savelkoul, H.F., 2009. Intradermal testing of horses with and without insect bite hypersensitivity in The Netherlands using an extract of native Culicoides species. Vet. Dermatol. 20, 607-614.

Stephan, A., Clausen, P.H., Bauer, B., Steuber, S., 2009. PCR identification of Culicoides dewulfi midges (Diptera: Ceratopogonidae), potential vectors of bluetongue in Germany. Parasitol. Res. 105, 367-371.

Sunnucks, P., Hales, D.F., 1996. Numerous transposed sequences of mitochondrial cytochrome oxidase I-II in aphids of the genus Sitobion (Hemiptera: Aphididae). Mol. Biol. Evol. 13, 510-524.

Tamura, K., Dudley, J., Nei, M., Kumar, S., 2007. MEGA4: Molecular evolutionary genetics analysis (MEGA) software version 4.0. Mol. Biol. Evol. 24, 1596-1599.

van der Rijt, R., van den Boom, R., Jongema, Y., van Oldruitenborgh-Oosterbaan, M.M., 2008. Culicoides species attracted to horses with and without insect hypersensitivity. Vet. J. 178, 91-97.

Waugh, J., 2007. DNA barcoding in animal species: progress, potential and pitfalls. Bioessays 29, 188-197.

Wilson, A.D., Heesom, K.J., Mawby, W.J., Mellor, P.S., Russell, C.L., 2008. Identification of abundant proteins and potential allergens in Culicoides nubeculosus salivary glands. Vet. Immunol. Immunopathol. 122, 94-103. 
Wirth, W.W., Ratanaworabhan, N.C., Blanton, F.S., 1974. Synopsis of the genera of Ceratopogonidae (Diptera). Ann. Parasitol. Hum. Comp. 49, 595-613.

Yadin, H., Brenner, J., Bumbrov, V., Oved, Z., Stram, Y., Klement, E., Perl, S., Anthony, S., Maan, S., Batten, C., Mertens, P.P., 2008. Epizootic haemorrhagic disease virus type 7 infection in cattle in Israel. Vet. Rec. 162, 53-56.

Yao, Y., Nellaker, C., Karlsson, H., 2006. Evaluation of minor groove binding probe and Taqman probe PCR assays: Influence of mismatches and template complexity on quantification. Mol. Cell. Probes 20, 311-316.

Zhang, D.-X., Hewitt, G.M., 1996. Nuclear integrations: challenges for mitochondrial DNA markers. Trends Ecol. Evol. 11, 247-251.

Zimmerli, U., Herholz, C., Schwermer, H., Hofmann, M., Griot, C., 2010. Afrikanische Pferdepest und equine Encephalosis: Muss sich die Schweiz vorbereiten? Schweiz. Arch. Tierheilkd. 152, 165-175. 
578 Figure 1. Dendrograms inferred from partial mitochondrial COI gene sequences of Culicoides

579 spp. from A. the Obsoletus group (C. obsoletus, C. scoticus, $C$. chiopterus) and $C$. dewulfi

580 and B. the Pulicaris group (C. pulicaris, C. lupicaris, C. deltus, C. grisescens) and Culicoides

581 sp. Depicted are all haplotypes identified in the three investigated regions in Switzerland

582 (Alps, Midland north of the Alps, South of the Alps). The number of isolates analyzed per

583 taxonomic unit is given in Table 1. Included are single sequences from C. imicola (C. imi),

584 Forcipomyia sp. (Forc. sp.), C. pulicaris (C. pul) (Fig 1A), C. obsoletus (C. obs) (Fig 1B) and

585 corresponding Culicoides GenBank entries if available. Sequences were aligned with

586 ClustalW and the tree was deduced from Neighbour-Joining (NJ) analyses using the

587 software MEGA, version 4.1 (Tamura et al., 2007). Bootstrap values are given on the nodes.

588 Sequences from GenBank are supplemented with the country origin of the midge (BG

589 Bulgaria, ES Spain, GB Great Britain). 
Fig. 1A

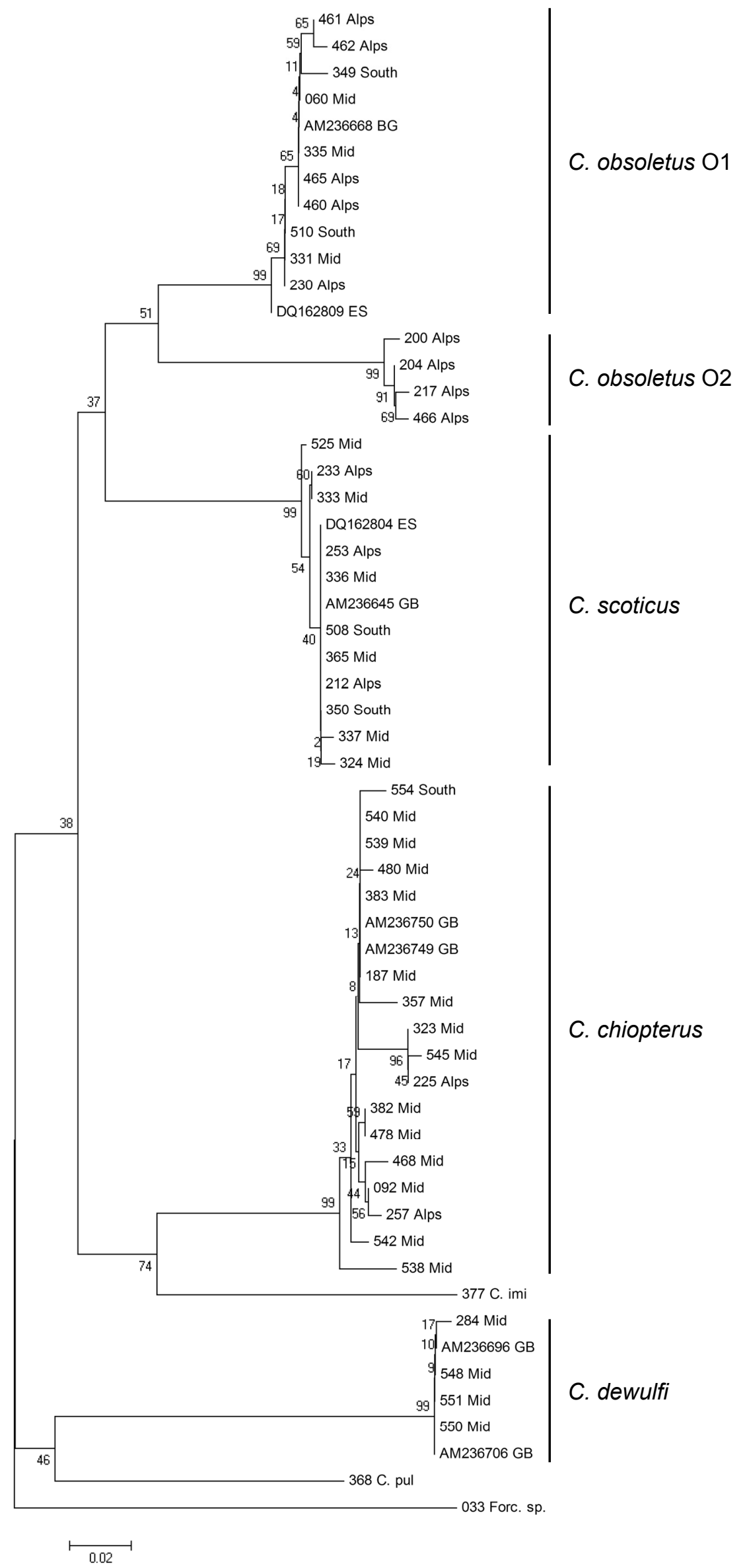


Fig. 1B

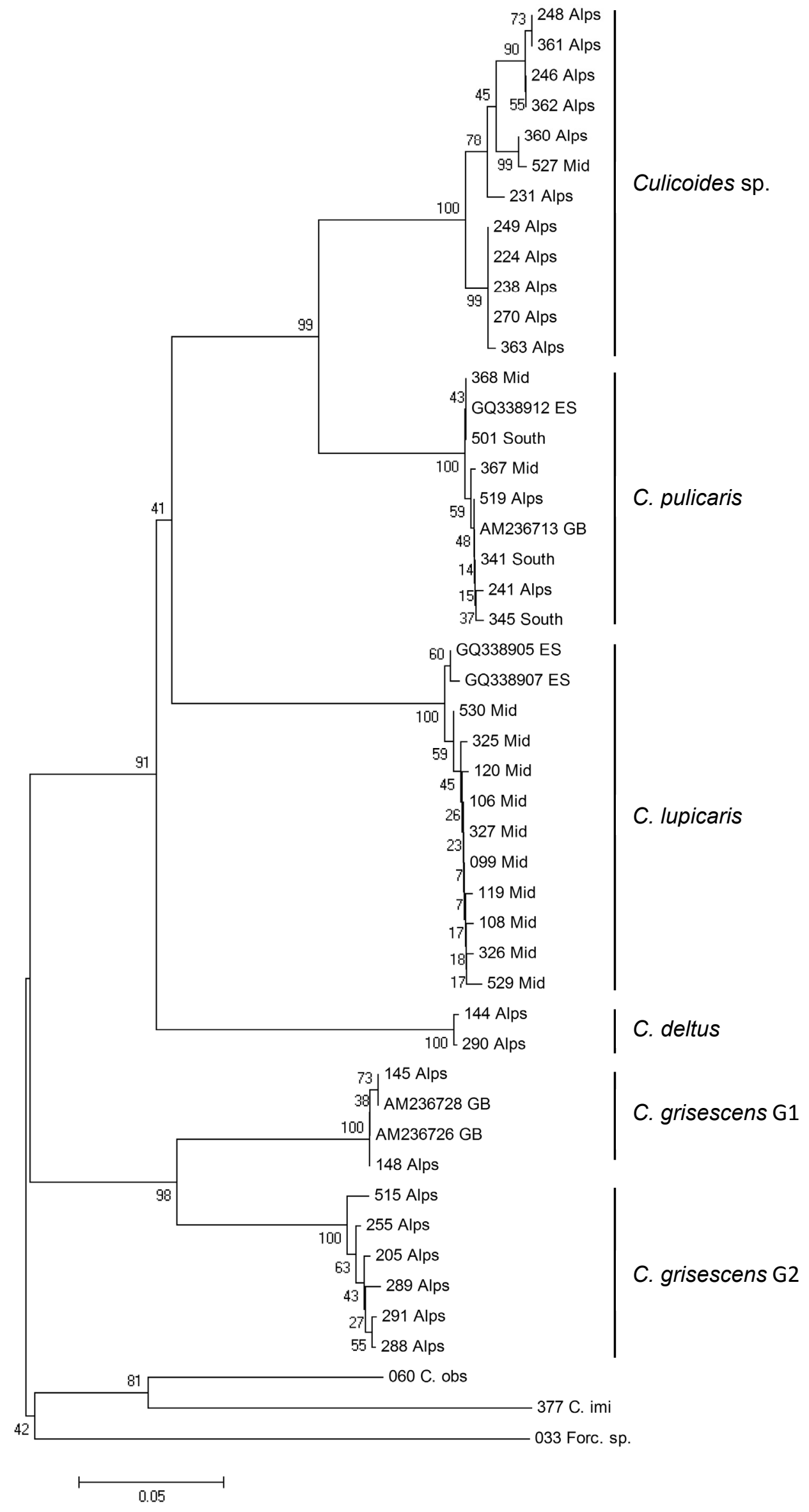


1 Table 1: Trapping regions and number of midges (Ceratopogonidae) investigated. Culicoides

2 identification was based on morphological and/or genetic (partial sequence of $\mathrm{mt}$ COI gene)

3 analyses.

\begin{tabular}{llll}
\hline Species & & \multicolumn{2}{l}{ Trapping regions in Switzerland $^{1}$} \\
\hline A. Culicoides for which real-time & Alps & Midland & South \\
PCRs were evaluated in this study & & & \\
C. chiopterus & 2 & 25 & 1 \\
C. deltus & 7 & 0 & 0 \\
C. dewulfi & 0 & 5 & 0 \\
C. grisescens $\mathrm{G1}^{3}$ & 7 & 0 & 0 \\
C. grisescens $\mathrm{G}^{3}$ & 12 & 0 & 0 \\
C. Iupicaris & 0 & 20 & 0 \\
C. obsoletus $\mathrm{O} 1$ & 7 & 57 & 4 \\
C. obsoletus $\mathrm{O} 2$ & 9 & 0 & 0 \\
C. pulicaris & 2 & 13 & 11 \\
C. scoticus & 5 & 97 & 2 \\
Culicoides sp. & 33 & 1 & 0
\end{tabular}

B. Other Culicoides spp.

C. brunnicans

C. circumscriptus

$0 \quad 0$

C. comosioculatus

$4 \quad 4$

C. duddinstoni

20

C. fascipennis

$1 \quad 0$

C. festivipennis

$1 \quad 0$

C. furcillatus

26

C. jurensis

C. kibunensis

C. pallidicornis

C. punctatus

C. reconditus

C. segnis

0

30

$0 \quad 0$

$0+1$

$3 \quad 7$

$8-1$

$0 \quad 0$

C. Non-biting Ceratopogonidae

Atrichopogon sp.

Brachypogon spp.

Dasyhelea spp.

Forcipomyia spp.

Serromyia sp.

$\begin{array}{lll}1 & 0 & 0 \\ 2 & 0 & 0 \\ 0 & 2 & 0 \\ 0 & 15 & 0 \\ 0 & 1 & 0\end{array}$

4

$5 \quad{ }^{1}$ Alps (altitude $1000-2200 \mathrm{~m}$ ), Midland (north of the Alps, altitude $400-700 \mathrm{~m}$, Atlantic

6 climate) and South (south of the Alps, altitude $<400 \mathrm{~m}$; climate influenced by the

7 Mediterranean Sea). 
$8 \quad{ }^{2}$ In addition, a real-time PCR was designed and evaluated for C. imicola of which individuals

9 originating from Corsica (France) were available (kindly provided by J.-C. Delécolle).

$10 \quad{ }^{3} \mathrm{PCR}$ assay designed to be specific for both C. grisescens $\mathrm{G} 1$ and G2. 
1 Table 2: Sequences of primers and probes (5' - 3') for real-time PCR assays, and cross-reactivities observed.

\begin{tabular}{|c|c|c|c|}
\hline $\begin{array}{l}\text { Attempted } \\
\text { specificity }\end{array}$ & \multicolumn{2}{|c|}{ Primers and probes (optimal concentration in $\mathrm{nM}$ ) } & Cross-reactivity ${ }^{1}$ with other \\
\hline C. chiopterus & $\begin{array}{l}\text { chi_F } \\
\text { chi_R } \\
\text { chi_P }\end{array}$ & $\begin{array}{l}\text { AGGTATTAGTTCTATTTTAGGGGCT }(300) \\
\text { AATGATAAAAGRAGTAAAATTGCAGTKAGA (300) } \\
\text { FAM -CTATTATTAATATACGTTCTAATGGAATAAC-NFQ-MGB (100) }\end{array}$ & C. imicola (28), C. scoticus (30) \\
\hline C. deltus & $\begin{array}{l}\text { del_F } \\
\text { del_R } \\
\text { del_P }\end{array}$ & $\begin{array}{l}\text { TGGAACTGGATGAACCGTA (300) } \\
\text { AGAAGAAATYCCTGCTAAATGTAGT (300) } \\
\text { Cy5 -TCACGCTGGGGCCTCAGTAGATTTAGCA-BHQ-2 (50) }\end{array}$ & Culicoides sp. $\left.{ }^{4}\right)(29)$ \\
\hline C. dewulfi & $\begin{array}{l}\text { dew_F } \\
\text { dew_R } \\
\text { dew_P }\end{array}$ & $\begin{array}{l}\text { ATGCCGGAGCCTCG (300) } \\
\text { GGGTATTTGTTCAAATAATATTCTATTTGGT (300) } \\
\text { Cy5 -CCTGCATTTGGCAGGAATTAGCTCAATCC-BHQ-2 (50) }\end{array}$ & None \\
\hline $\begin{array}{l}\text { C. grisescens } \\
\mathrm{G} 1+\mathrm{G} 2\end{array}$ & $\begin{array}{l}\text { gri_F } \\
\text { gri_R } \\
\text { gri_P }\end{array}$ & $\begin{array}{l}\text { CMYTWCATYTWGCAGGTATYTCTTCA }(300) \\
\text { CTAARACTGGRAGRGAWARAAGTAAAAG }(900) \\
\text { FAM -TGGAATTACATTTGATCGAATAC-NFQ-MGB (200) }\end{array}$ & Culicoides sp. ${ }^{4)}(30)$ \\
\hline C. imicola & $\begin{array}{l}\text { imi_F } \\
\text { imi_R } \\
\text { imi_P }\end{array}$ & $\begin{array}{l}\text { TCCTCGAATAAATAATATAAGTTTTTGAATATTA (300) } \\
\text { ACATTTGCYGATAATGGAGGA (300) } \\
\text { FAM -CCATCTATTACTCTTCTTTTATTAAG-NFQ-MGB (50) }\end{array}$ & None \\
\hline C. Iupicaris & $\begin{array}{l}\operatorname{lup}_{\text {lup_F }} \\
\text { lup_R } \\
\text { lup_P }\end{array}$ & $\begin{array}{l}\text { AATTTCTTCTATTCTAGGAGCTGTG }(300) \\
\text { GCCAAAACTGGTAAAGAAAGTAATAAT }(300) \\
\text { ROX- ATGCGATCTAATGGAATTTCATTCGACCGTATACC-BHQ-2 (100) }\end{array}$ & None \\
\hline C. obsoletus $\mathrm{O} 1$ & $\begin{array}{l}\text { obs1_F } \\
\text { obs1_R } \\
\text { obs1_P }\end{array}$ & $\begin{array}{l}\text { GAAAAYGGAGCAGGAACC (50) } \\
\text { GAAAAAATAGCCAAATCTACAGAA (300) } \\
\text { VIC -TGCATGAGAGATATTAGATGAAAGG-NFQ-MGB (100) }\end{array}$ & C. scoticus ${ }^{4)}(29)$ \\
\hline C. obsoletus $\mathrm{O} 2$ & $\begin{array}{l}\text { obs2_F } \\
\text { obs2_R } \\
\text { obs2_P }\end{array}$ & $\begin{array}{l}\text { GGAGCCGTTAATTTTATTACAACC }(50) \\
\text { CTGCTAATACAGGTAAAGATAGTAGG (50) } \\
\text { FAM-TGGAATAACTTTCGATCGAATACCTTTATTTGTCTGATCAGT-BHQ-1 (100) }\end{array}$ & $\begin{array}{l}\text { C. scoticus (27/28), C. } \\
\text { chiopterus }^{4)}(30)\end{array}$ \\
\hline C. pulicaris & $\begin{array}{l}\text { pul_F } \\
\text { pul_R } \\
\text { pul_P }\end{array}$ & $\begin{array}{l}\text { CGGAATCTCATTTGACCGTATG }(300) \\
\text { AATGTTTCGATCAGTTAAAAGTATYGTG (300) } \\
\text { Cy5 -ACTGTTACTCTCTCTTCCCGTATTAGCCGGAGC-BHQ-2 (100) }\end{array}$ & None \\
\hline C. scoticus & $\begin{array}{l}\text { Sco_F } \\
\text { Sco_R } \\
\text { Sco_P }\end{array}$ & $\begin{array}{l}\text { CCCCCACTYTCAGCA }(300) \\
\text { GCTAATACCTGCTAAATGYAGA (300) } \\
\text { ROX -TGTCTCCCATGCAGGAGCCTCAGTTGA-BHQ-2 (50) }\end{array}$ & C. chiopterus $\left.{ }^{4}\right)(26)$ \\
\hline Culicoides sp. & $\begin{array}{l}\text { Csp_F } \\
\text { Csp_R } \\
\text { Csp_P }\end{array}$ & $\begin{array}{l}\text { AACGGAGCCGGTACC (300) } \\
\text { YCCGAGAATTGAAGAAATACCG (300) } \\
\text { HEX-TGCCAATATTTCTCATGCCGGAGCATCTGTAGATTTA-BHQ-1 (100) }\end{array}$ & None \\
\hline
\end{tabular}


$3{ }^{1)} \mathrm{Ct}$ value $\leq 30$ cycles when tested with $5 \times 10^{9}$ cloned targets. No cross-reactivity (i.e. Ct value $\leq 40$ cycles) at all was observed when testing $5 \mathrm{x}$

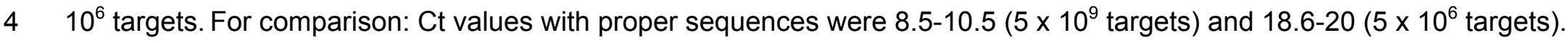

$5 \quad{ }^{2)}$ Species and numbers of haplotypes tested: C. chiopterus: 3; C. circumscriptus: 2; C. comosioculatus: 1; C. deltus: 2; C. dewulfi: 1; C.

6 fascipennis: 1; C. festivipennis: 1; C. grisescens G1: 2; C. grisescens G2: 1; C. imicola: 1; C. lupicaris: 1; C. obsoletus O1: 4; C. obsoletus O2: 3;

7 C. pallidicornis: 1; C. pulicaris: 2; C. punctatus: 2; C. scoticus: 3; Culicoides sp.: 4; one haplotype each of other Ceratopogonidae: Atrichopogon

8 sp.; Brachypogon sp.; Dasyhelea sp.; Forcipomyia sp.; Serromyia sp.

9 3) MGB: minor groove binding probe.

$10{ }^{4)}$ Only one haplotype of the indicated Culicoides species positive; for number of haplotypes tested per species see footnote 2 above. 